\title{
Liberalisation and Jobless Growth in Developing Economy
}

Soumyatanu Mukherjee

School of Economics, CREDIT \& GEP, University of Nottingham, Nottingham, U.K.

\begin{abstract}
This paper explains why a developing country may experience a jobless growth in the organised sectors during liberalised regime within the framework of a three-sector mobile capital version of Harris-Todaro type general equilibrium model describing rural-urban migration with agricultural dualism and a non-traded intermediate input. Main findings support the fact that as a consequence of different trade reform policies, organised sectors have experienced increased competition from foreign markets which has forced them to lax labour laws, with the freedom to switch towards more capitalintensive techniques of production, resulting retrenchment of relatively less productive workers and ending up with a jobless growth under the liberalised regime. These results are particularly interesting for their contradiction to the predictions of the standard Harris-Todaro model.
\end{abstract}

\footnotetext{
* Corresponding Author: Soumyatanu Mukherjee; School of Economics, CREDIT \& GEP, University of Nottingham, Sir Clive Granger Building, University Park, NG7 2RD, Nottingham, United Kingdom; Indian; Tel: +44 1159515620, Fax: +44 1159514159, E-mail: Soumyatanu.Mukherjee@nottingham.ac.uk.

Acknowledgements: This research is funded by an Economic and Social Research Council (ESRC), University of Nottingham Doctoral Training Centre (DTC) studentship (reference number ES/J500100/1). I am grateful to the anonymous referees and the editors of this journal for their valuable and helpful comments on an earlier version of this paper. I also must remain grateful to Professor Oliver Morrissey, Dr Markus Eberhardt and Prof Daniel Seidmann for their valuable suggestions and comments. The usual disclaimer applies.
} 
JEL Classifications: F11, F16, J21, O24

Key words: Trade Liberalisation, Labour Market Reform, Agricultural Dualism, Jobless Growth, Non-traded Intermediate Input, Urban Unemployment

\section{Introduction}

In this era of globalisation, government has lesser and lesser scope for market intervention. One popular belief is that one can best understand the problems of a Less Developed Country (LDC) with reference to the international environment to which it belongs. Thus, the problems of underdevelopment must be approached in a global context. So the claim is: if countries adopt an outward-oriented policy that aims to reduce all barriers to free trade, all of the problems developing countries face will gradually diminish, including that of increasing urban unemployment. From the available empirical evidence such as Bhaduri (2007), Bhalotra (1998), it is evident that India observed stagnation in the organised sector employment in the late 1980s. Surprisingly, even after extensive economic reforms in 1991, India is still facing substantial adjustment costs in implementing economic liberalisation programs. ${ }^{1}$ As stressed in Nagraj (2009), after reform, India immediately witnessed a boom for four years, 1992 1996, followed by a retrenchment, but soon India began to experience loss in employment of $15 \%$ of the workforce employed in 11 major industry groups in the organised manufacturing in 17 major states from 1996 to 2001. According to the most recent National Sample Survey (NSS) round conducted from July 2009 to June 2010, organised sector employment reduced dramatically between 2004 2005 and 2009 2010, especially when compared to the earlier five-year period. This is surprising, given that this was a period of very rapid GDP expansion, which points to the growing possibility of jobless growth in the Indian economic reform period. One possible reason may be that in spite of the output and investment boom, trade reform measures have made India increasingly reliant on external economic factors like other developing countries, which have become increasingly volatile (Kaplinsky 2001). As a result of rapid openning for competition, the labour laws have been weakened with greater substitution from labour to capital, leading

${ }^{1}$ See Jha (2003) in this context. 
to increased productivity of the remaining employees. According to the relevant NSS rounds, unemployment rate has gone up from 6\% in 1993 1994 to 7.3\% in 1999 2000. The growth rate of labour force was $2.43 \%$ per annum (p.a.) between 1983 1984 and 1993 1994, and then it came down to 1.31\% p.a. between 1993 1994 and 1999 2000.

Using the state-level data on India's registered manufacturing industries from 1980 2009, we have found that the employment pattern in the urban manufacturing industries does not exhibit any significant upward trends, in most cases they are rather decreasing or stagnant. The following figure illustrates the case for West Bengal, Gujrat, and Delhi as an example.

\section{Figure 1. Trend in Organised sector Employment}

(1989 2009)

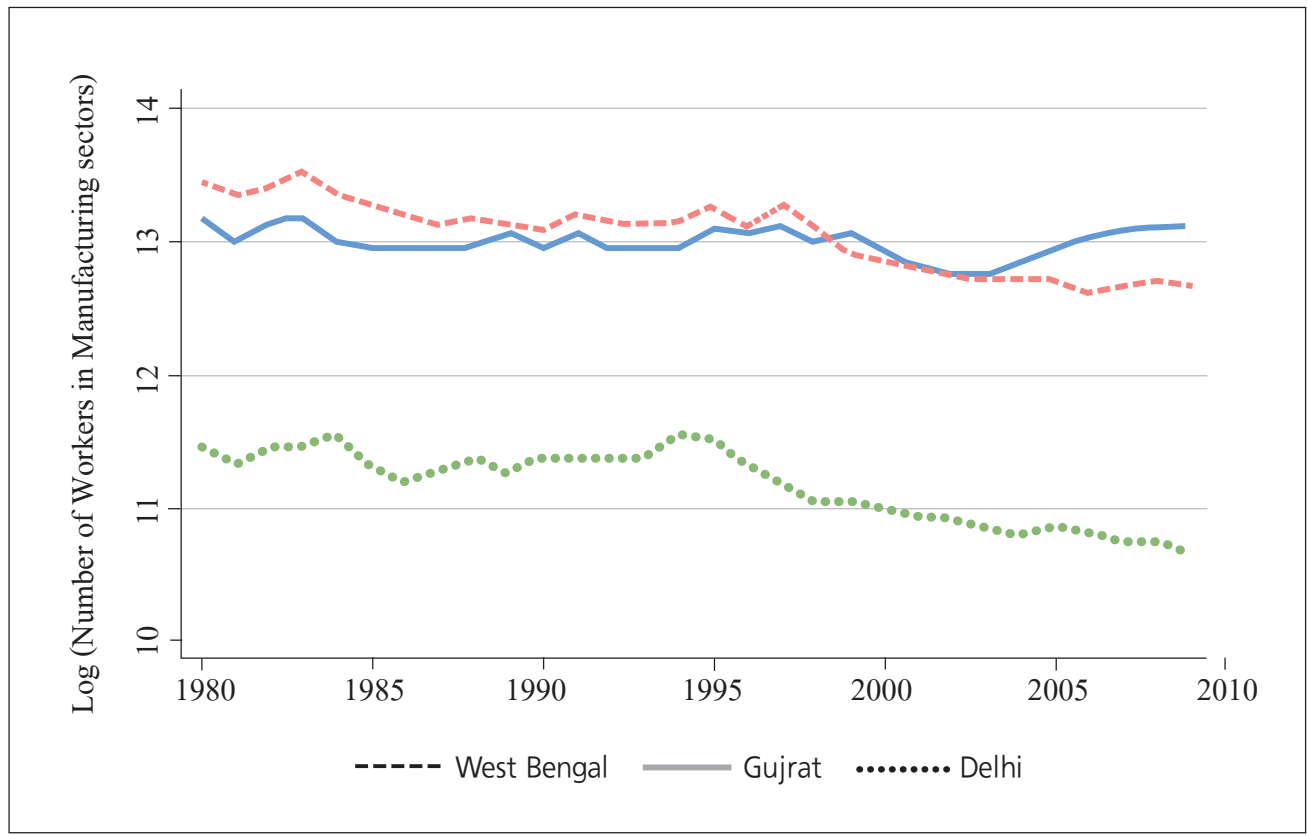

(Source) Annual Survey of Industries, Government of India

Therefore, one can infer that trade liberalisation during the 1990s did not result in any significant increase in productive job opportunities for the organised sector labour force.

\footnotetext{
${ }^{2}$ Other states and union territories show similar trends in employment pattern in organised sectors. So for the sake of brevity we have chosen the three most important states.
} 
Since the withdrawal of the non-tariff barriers coupled with large and indiscriminate cut in import tariffs, the domestic organised sector firms which have been protected as they have not been able to cope with foreign competitors and have been forced to pull their shutters down, accumulating to a more widespread unemployment problem. The unorganised sector expanded but has not been able to absorb these large number of retrenched workers from the organised sector. The consequence has been a steep increase in the level of unemployment. On the other hand, this will not hamper the growth of the economy as the organised sector benefits from the higher productivity of the remaining workforce and can emerge competitive in the international market. This has generated scepticism regarding the allocation of the benefits from reform. The growth India is experiencing in this liberalised regime, is indeed jobless (Indiresan 2002, Sen 2005). This may tempt us to analyse the impact of economic reform on welfare and unemployment in terms of a general equilibrium framework. However, the simple two-sector mobile capital version of Harris-Todaro (Harris and Todaro 1970) model (a' la Corden and Findlay 1975) may not appropriately describe the complex nature of a low income developing economy, since the presence of agricultural dualism and non-traded goods remain the two important features of such an economy. The nontraded goods may be either intermediate inputs or final commodities. Chaudhuri (2007) incorporated the agricultural dualism to analyse why the developing countries are luring for foreign capital using a non-traded final commodity while Mukherjee (2012) used non-traded intermediate input to examine the consequences of a liberalised investment policy, that is, the impacts of foreign capital inflow on welfare and the level of urban unemployment in terms of a three sector mobile capital version of Harris-Todaro (hereafter HT) model. One should keep in mind, however, that economic reforms, involve not only a liberalised investment policy but also removal of protectionist policy and structural reforms like deregulating the labour market. The purpose of this paper is to build a theoretical model to yield predictions about the possibility of jobless growth in a developing economy with labour market imperfection.Agricultural dualism in the rural economy has advanced agricultural sector producing a non-traded intermediate input $^{3}$ using capital along with labour and land for the agro-based urban industry. This approach, to capture theoretically the impacts of trade liberalisation and labour market reform within the agricultural dualism and non-traded intermediary is, to the best of my knowledge, a novel extension of Mukherjee (2012).

\footnotetext{
3 Although some papers (Marjit and Beladi 1996, Yabuuchi and Beladi 2001) assume existence of traded intermediary, assuming the intermediate sector to be non-traded seems more realistic in this context. For details see Mukherjee (2012).
} 


\section{The Model}

Consider a small open economy, broadly divided into an urban manufacturing sector and a rural sector, which is sub-divided into backward agricultural sector (sector 1) and advanced agricultural sector (sector 2). Sector 1 uses labour and land as inputs, and is assumed to be the export sector of the economy. Sector 2 produces a commercial agricultural crop as an intermediate input for the urban manufacturing sector using land, labour and capital. Finally, the urban manufacturing sector (sector 3) may be an agro-based industry that uses labour, capital and the intermediate input. Sector 3 is the import-competing sector of the economy and is protected by an import tariff . ${ }^{4}$ The per unit requirement of the intermediate input is assumed to be technologically fixed in urban sector. ${ }^{5}$ Workers in urban sector earn an institutionally given wage, $W^{* 6}$, while the wage rate in the other two sectors, $W$, is market determined. Therefore, labour is perfectly mobile between backward and advanced agricultural sectors, but imperfectly mobile between urban manufacturing and the rest of the economy. Production functions exhibit constant returns to scale with diminishing marginal productivity to each factor. The two wages are related by the Harris-Todaro condition of migration equilibrium with $W<W^{*}$. Agricultural commodity is chosen as numeraire, so its price is set equal to unity.

The following notations are used:

$W=$ competitive rural wage rate for labour $(L)$;

$W^{*}=$ institutionally given wage rate in urban sector;

$R=$ rate of return to land $(N)$;

$r=$ rental rate return to capital $(K)$;

$a_{j i}=$ amount of the $j^{\text {th }}$ input used to produce 1 unit of the $i^{\text {th }}$ good ;

$X_{i}=$ output of sector $i$;

$L_{u}=$ urban unemployment level;

$P_{2}=$ domestic price of non-traded input;

\footnotetext{
${ }^{4}$ We assume ad-valorem equivalence of any quantitative or other restrictions on imports, such as quotas.

${ }^{5}$ It rules out the possibility of substitution between the non-traded input and other factors of production in urban sector.

${ }^{6}$ This is a simplifying assumption. Assuming each urban sector firm has a separate labour union, the unionised wage function can be derived as a solution to a Nash bargaining game between the representative firm and the representative union. This function has been derived in Chaudhuri and Mukhopadhyay (2010), p. 33-35.
} 
$P_{3}=$ international price of good 3;

$t=a d$-valorem rate of tariff;

$\theta_{j i}=$ cost share of $j^{\text {th }}$ input in the production of $\operatorname{good} i$;

$\lambda_{j i}=$ share of sector $i$ in the total employment of input $j$.

$\wedge=$ proportional change .

The three zero-profit conditions are given by

$$
\begin{gathered}
W a_{L 1}+R a_{N 1}=1 \\
W a_{L 2}+R a_{N 2}+r a_{K 2}=P_{2} \\
W^{*} a_{L 3}+r a_{K 3}+P_{2} a_{23}=(1+t) P_{3}
\end{gathered}
$$

Factor Market Equilibrium conditions are given by

$$
a_{L 1} X_{1}+a_{L 2} X_{2}+a_{L 3} X_{3}+L_{U}=L
$$

By Harris-Todaro Migration Equilibrium ${ }^{7}$ condition,

$$
\left(W^{*} a_{L 3} X_{3} /\left(a_{L 3} X_{3}+L_{U}\right)\right)=W
$$

Inserting $\left(a_{L 3} X_{3}+L_{U}\right)=\left(W^{*} a_{L 3} X_{3} / W\right)$ in Equation (4a) we get

$$
\begin{gathered}
\left(\frac{W^{*}}{W}\right) a_{L 3} X_{3}+a_{L 2} X_{2}+a_{L 1} X_{1}=L \\
a_{K 2} X_{2}+a_{K 3} X_{3}=K
\end{gathered}
$$

${ }^{7}$ This is, of course, globally asymptotically stable in our model. 


$$
a_{N 1} X_{1}+a_{N 2} X_{2}=N
$$

The demand for non-traded input must equal its supply. So,

$$
X_{2}^{D}=X_{2}=a_{23} X_{3}
$$

The economy's social welfare is measured by strictly quasi-concave social welfare function as,

$$
V=V\left(D_{1}, D_{3}\right)
$$

where

$D_{1}=$ Domestic consumption of agricultural commodity 1 by the society $D_{3}=$ Domestic consumption of the final manufacturing product by the society

We implicitly assume that the non-tradable produced by advanced agricultural sector are not used for consumption purpose.

National Income at domestic prices is

$$
Y=D_{1}+P_{3}^{*} D_{3}=W L+R N+r K_{\mathrm{D}}-t P_{3}\left(D_{3}-X_{3}\right)
$$

It is not a decomposable system. The working of our general equilibrium model is as follows:

Given $W^{*}, P_{3}, t ; W, R$ are $r$ determined from our price-system given by Equations (1) (3) as functions of $P_{2}$. Once factor prices are determined, factor coefficients are also determined as functions of $P_{2}$. Then from Equations (4c) (6) $X_{1}, X_{2}$ and $X_{3}$ are determined as functions of $P_{2}$. Finally $P_{2}$ is obtained from Equation (7).

Following Mukherjee (2012), I also assume that sector 2 is relatively more landintensive compared to sector 1 in both physical and value terms. 


\section{A. Comparative statics: reduction in protection}

Taking total differentiation of Equations (1) (3), using envelope conditions and Cramer's rule we get

$$
\begin{gathered}
\widehat{W}=-\frac{\theta_{N 1}}{|\theta|}\left[\left(\theta_{K 3}+\theta_{23} \theta_{K 2}\right) \widehat{P_{2}}-\theta_{K 2} T \hat{t}\right] \\
\hat{R}=\frac{\theta_{L 1}}{|\theta|}\left[\left(\theta_{K 3}+\theta_{23} \theta_{K 2}\right) \widehat{P_{2}}-\theta_{K 2} T \hat{t}\right] \\
\hat{r}=\frac{\left(\theta_{L 1} \theta_{N 2}-\theta_{N 1} \theta_{N 2}\right)}{|\theta|}\left(T \hat{t}-\theta_{23} \widehat{P_{2}}\right)
\end{gathered}
$$

where

$$
|\theta|=\theta_{K 3}\left(\theta_{L 1} \theta_{N 2}-\theta_{N 1} \theta_{L 2}\right)
$$

and,

$$
T=(t /(1+t))>0
$$

Now totally differentiating Equations $(4 b) \sim(7)$, using (10) (12) and solving we get

$$
\begin{aligned}
& \widehat{X_{2}}=\frac{1}{|\lambda|}\left[\left(\lambda_{N 1} \lambda_{K 3} C_{1}+\lambda_{L 1} \lambda_{K 3} C_{2}+\tilde{\lambda}_{L 3} \lambda_{N 1} C_{3}\right) \hat{P}_{2}-\right. \\
& \left.\left(\lambda_{L 1} \lambda_{K 3} C_{4}+\lambda_{N 1} \lambda_{K 3} C_{5}+\lambda_{N 1} \widetilde{\lambda_{L 3}} C_{6}\right) \hat{t}\right] \\
& \widehat{X_{3}}=\frac{1}{|\lambda|}\left[\left(\lambda_{N 1} \lambda_{N 2} C_{3}-\lambda_{L 1} \lambda_{K 2} C_{2}-\lambda_{L 2} \lambda_{N 1} C_{3}-\lambda_{N 1} \lambda_{K 2} C_{1}\right) \hat{P}_{2}\right. \\
& \left.-\left(\lambda_{L 1} \lambda_{N 2} C_{6}-\lambda_{L 1} \lambda_{K 2} C_{4}-\lambda_{L 2} \lambda_{N 1} C_{6}-\lambda_{K 2} \lambda_{N 1} C_{5}\right) \hat{t}\right]
\end{aligned}
$$


where all of the $C_{1}, C_{2}, C_{3}, C_{4}, C_{5}<0 .{ }^{8}$ Under the condition $\lambda_{L 3}$ is negligible ${ }^{9}, C_{6}<0$. It can be shown that by the stability condition in the market for non-traded input $(\Delta /|\lambda|)$ $<0{ }^{10}$ This implies $|\lambda|<0$ as $\Delta>0$.

$$
\widehat{P_{2}}=\frac{\hat{t}}{\Delta}\left[C_{6}\left(\lambda_{L 1} \lambda_{N 2}-\lambda_{L 2} \lambda_{N 1}-\lambda_{L 3} \lambda_{N 1}\right)-C_{4} \lambda_{L 1}-C_{5} \lambda_{N 1}\right]
$$

So if (i) $\tilde{\lambda}_{L 3} \cong 0$, (ii) $|\theta|=\theta_{K 3}\left(\theta_{L 1} \theta_{N 2}-\theta_{N 1} \theta_{L 2}\right)<0$ and $\left(\lambda_{L 1} \lambda_{N 2}-\lambda_{L 2} \lambda_{N 1}\right)<0$, then $\widehat{P}_{2}<0$, $\widehat{X_{2}}>0$ and $\widehat{X_{3}}<0$.

Differentiation of Equations (8) and (9) gives

$$
\frac{d V}{V_{1}}=d D_{1}+(1+t) P_{3} d D_{3}=J\left[\left(1-L_{1}\right) W \widehat{W}+t P_{3}\left(t P_{3} S \hat{t}-X_{3} \widehat{X_{3}}\right)\right]
$$

where $V_{1}=\frac{\partial V}{\partial D_{1}}, J=\frac{1+t}{\{1+(1-c) t\}}, S=\left(\frac{\partial D_{3}}{\partial P_{3}^{*}}\right)+\left(\frac{\partial D_{3}}{\partial Y}\right) D_{3}$ is the Slutsky's pure substitution term, and $C=(1+t) P_{3}\left(\frac{\partial D_{3}}{\partial Y}\right)$ is the marginal propensity to consume good 3 .

Now,

$$
d V / V_{1} \hat{t}=\left[\left\{\left(1-L_{1}\right) W \frac{\widehat{W}}{\hat{t}}-t P_{3} X_{3}\left(\frac{\widehat{X_{3}}}{\hat{t}}\right)\right\}+\left(t P_{3}\right)^{2} S\right]
$$

represents the impact of tariff-reduction on welfare.

$$
\widehat{W}=-\left(\frac{\theta_{N 1} \hat{t}}{|\theta|}\right)\left[\left\{C_{6}\left(\lambda_{L 1} \lambda_{N 2}-\lambda_{L 2} \lambda_{N 1}-\tilde{\lambda}_{L 3} \lambda_{N 1}\right)-C_{4} \lambda_{L 1}-C_{5} \lambda_{N 1}\right\}\left(\frac{\theta_{K 3} \theta_{23} \theta_{K 2}}{\Delta}\right)+\theta_{K 2} T\right]
$$

${ }^{8}$ See Appendix A for expressions of $C_{1}, C_{2}, C_{3}, C_{4}, C_{5}$ and $C_{6}$.

${ }^{9}$ This is a realistic assumption since for most of the low-income developing countries share of employment in the organised sector is likely to become negligible over time, as bulk of the workforce are engaged in informal jobs, including agriculture. For example, in India, more than $90 \%$ people are engaged in agriculture and other informal activities. The focus of this paper is such LDCs. This assumption has also been used in Marjit (2003). The assumption is about share of employment in the organised sector. To assume share of employment in the organised sector is negligible compared to the other sectors of the economy does not rule out the existence of unemployment in sector 3 , nor reduce the importance of sector 3. Empirically it only indicates that productivity has improved in sector 3 .

${ }^{10}$ See Appendix B for detailed derivation. 
So $\hat{W}<0$ when $\hat{t}<0$, if $|\theta|<0$ and $\left(\lambda_{L 1} \lambda_{N 2}-\lambda_{L 2} \lambda_{N 1}\right)<0$

From HT migration equilibrium we have

$$
L_{U}=\left[\left\{\left(\frac{W^{*}}{W}\right)-1\right\} a_{L 3} X_{3}\right]
$$

Now, totally differentiating the migration equilibrium condition we obtain

$$
\widehat{L_{U}}=\frac{\lambda_{L 3}}{\lambda_{L U}}[\underbrace{\left(\frac{W^{*}}{W}-1\right)\left(\widehat{a_{L 3}}+\widehat{X_{3}}\right)}_{<0, \text { centripetal force }}+\{\underbrace{-\left(\frac{W^{*}}{W}\right) \widehat{W}}_{>0, \text { centrifugal force }}\}]
$$

These lead to the following proposition:

Proposition 1: Tariff reduction may lead to stagnant employment situation in urban manufacturing sector if $\left|\widehat{X_{3}}\right| \cong|\widehat{W}|$ provided $\widetilde{\lambda}_{L 3} \cong 0$ and $|\theta|<0$. and sector 1 is relatively land-intensive than sector 2 in physical and value terms.

Proof. It is straightforward to argue from Equations (A1), (14), (15) and (17) when $\tilde{\lambda}_{L 3}$ is negligible and $|\theta|<0,\left(\lambda_{L 1} \lambda_{N 2}-\lambda_{L 2} \lambda_{N 1}\right)<0 ; C_{6}<0=>\widehat{X_{3}}<0 ; \widehat{P_{2}}<0 ; \widehat{W}<0$ when $\hat{t}<0$. Thus Equation (18) indicates the possibility of zero net job creation in the urban sector under the liberalised regime. The intuition is as follows.

A reduction in import tariff lowers the domestic price of the finished manufacturing (agro-based) good produced by urban manufacturing sector, thus shrinking this sector. Capital-intensive urban sector now demands less capital which in turn lowers the return to capital, $r$. This contraction of the urban sector reduces both demand and supply of the non-traded input produced by advanced agro-processing sector but as long as the urban manufacturing sector accounts for significantly low share of total employment, the demand-effect dominates and $P_{2}$ falls. Now in the Heckscher-Ohlin-Subsystem (HOSS) formed by the two agricultural sectors, the fall in $P_{2}$ induces a Stolper-Samuelson effect, following which $W$ falls but $R$ (return to land-capital) rises under the assumption $|\theta|<0$. 
Note that there will be four different impacts on social welfare: total wage income decreases as $W$ falls; rental income from land rises; return from mobile capital falls; and as $X_{3}$ falls, cost of tariff protection of the import-competing sector, $t P_{3} X_{3}$, falls.

Now let us explain Equation (18) which shows the effect on urban unemployment: (i) Sector 3 contracts. (ii) Since $\left(W^{*} / r\right)$ rises labour-output ratio in sector $3, a_{L 3}$, falls. Therefore, the number of jobs available in the urban sector, $a_{L 3} X_{3}$, falls. This decreases the expected urban wage for every prospective rural migrant leading to a reverse migration from urban to rural sector. This is the centripetal force reducing the extent of urban unemployment. However, as competitive rural wage falls, it will induce the rural workers to leave the rural sectors and to join the urban unemployment pool. This is the centrifugal force worsening the problem. If the relative strengths of these two opposite forces are more or less equal to each other, there may be no net job creation in the urban sector. Also, if the magnitude of the centrifugal force is larger, the economy might experience significant job losses in the urban sector even adopting this policy of tariff reform.

However as pointed out before, the economy-wide social welfare may improve. This indicates to the possibility of the economy to experience jobless growth in this liberalised regime.

The organised manufacturing sector accounts for a small share of total employment in most of the low-income developing countries and this extension adds insight into why for an agriculture-dominated less developing economy, trade liberalisation might be welfare improving but there may be significant job losses or stagnation in urban employment.

\section{B. Reduction in bargaining strength of the labour union}

Assumption is made of institutionally given wage in the urban sector and take into account the fact that the urban sector faces a unionised labour market. So $W^{*}$ is now endogenously determined as,

$$
W^{*}=W^{*}(W, U)
$$

Where $U$ is the bargaining power of the labour unions. And we have, $W^{*}=W$ for 
$U=0, W^{*}>W$ for $U>0 ;\left(\partial W^{*} / \partial W\right),\left(\partial W^{*} / \partial U\right)>0$. So Equation (3) can be re-written as,

$$
W^{*}(W, U) a_{L 3}+r a_{K 3}+P_{2} a_{23}=(1+t) P_{3}
$$

A policy of labour-market reform takes the form of government intervention to reduce the bargaining strength of the labour-union $(U)$, leading to a decrease in the unionised wage rate $\left(W^{*}\right){ }^{11}$

Accordingly, the comparative statics exercise yield:

$$
\begin{gathered}
\widehat{X_{2}}=\frac{1}{|\lambda|}\left(\lambda_{L 1} \lambda_{K 3} B_{2}+\lambda_{N 1} \lambda_{K 3} B_{1}+\lambda_{N 1} \lambda_{L 3} B_{3}\right) \widehat{W}^{*} \\
\widehat{X_{3}}=\frac{1}{|\lambda|}\left(\lambda_{L 1} \lambda_{N 2} B_{3}-\lambda_{L 1} \lambda_{K 2} B_{2}-\lambda_{L 2} \lambda_{N 1} B_{3}-\lambda_{K 2} \lambda_{N 1} B_{1}\right) \widehat{W}^{*}
\end{gathered}
$$

See appendix for the expressions of $B_{1}, B_{2}$, and $B_{3}$ (Equation A2).

As explained previously, under the assumption that sector 2 is relatively labourintensive than sector 1 in value-sense (i.e., $|\theta|<0$ ), we have all $B_{1}, B_{2}$ are $<0$. But sign of $B_{3}$ is ambiguous. If $\widetilde{\lambda}_{K 2} \cong 0$ (i.e., proportion of capital used in sector 2 is negligible), $B_{3}<0$. Therefore, from Equations (19) and (20), when $\widehat{W}^{*}<0$, under the sufficient conditions $\tilde{\lambda}_{K 2} \cong 0,|\theta|<0$ and since we already have $|\lambda|<0$, we would have $\widehat{X_{2}}, \widehat{X_{3}}>0$.

Accordingly, we have

$$
\widehat{P_{2}}=-\left(\frac{W^{*}}{\Delta}\right)\left[B_{3}\left(\lambda_{L 1} \lambda_{N 2}-\lambda_{L 2} \lambda_{N 1}\right)-B_{2} \lambda_{L 1}-B_{1} \lambda_{N 1}\right]
$$

As stated earlier, $\Delta>0$.

\footnotetext{
${ }^{11}$ Several empirical studies (Bhalotra 2002) have noted that in India, organised workers in the large firms are often keeping wages higher than the supply price of labour due to strong labour regulations through collective bargaining (offer of negotiations, strikes etc.) and restricted mobility of the labour in the organised sectors through various labour laws (Industrial Disputes Act 1947). As a consequence Indian policymakers, after the economic reform, started to seriously think over reformulating labour laws to curb union power to mark up wages, so that as a consequence unionised wage would fall. This assumption of existence of labour market distortion in the organised sector seems relevant for developing countries like India. For similar treatment in theoretical models, Mukherjee (2012).
} 
So when $\widehat{W^{*}}<0, \widehat{P_{2}}>0$ if $\lambda_{K 2} \cong 0$ and $|\theta|<0,|\theta|<0$ and $\left(\lambda_{L 1} \lambda_{N 2}-\lambda_{L 2} \lambda_{N 1}\right)<0$.

Finally, we have

$$
\widehat{W}=\left(\frac{\theta_{N 1} \widehat{W}^{*}}{|\theta|}\right)\left[\begin{array}{c}
\left\{B_{3}\left(\lambda_{L 1} \lambda_{N 2}-\lambda_{L 2} \lambda_{N 1}\right)-B_{2} \lambda_{L 1}-B_{1} \lambda_{N 1}\right\} \\
\left(\frac{\theta_{K 3}+\theta_{23}+\theta_{K 2}}{\Delta}\right)+\theta_{K 2}+\theta_{L 3}
\end{array}\right]
$$

When $\widehat{W}^{*}<0$, we have $\widehat{W}>0$ if $\lambda_{K 2} \cong 0$ and $|\theta|<0,\left(\lambda_{L 1} \lambda_{N 2}-\lambda_{L 2} \lambda_{N 1}\right)<0$. Therefore we are now in a position to state the following proposition.

Proposition 2: Competitive wage rises following a policy of labour-market reform if $\lambda_{K 2} \cong 0$ and sector 1 is relatively land-intensive than sector 2 in physical and value terms.

Proof. Government intervention to curb the bargaining power of labour-union, leading to a reduction in the unionised wage, makes it possible for the urban sector (sector 3 ) to save on labour input and raises the effective price of the commodity (net of labour cost) as faced by the manufacturing producers. This helps sector 3 to expand. Note that ambiguous sign of $B_{3}$. There will be no effect on expansion of sector 3 as long as proportion of workforce employed in sector 3 is negligible. This will increase the demand for capital given supply as the capital-intensive sector 3 will demand more capital for its expansion. That will make capital relatively costly with rise in $r$. At the same time, sector 3 will demand more of the non-traded input produced by sector 2 . As output of sector 2 is used in a fixed proportion in sector 3, that will enable sector 2 to expand. Since $r$ rises, it will tend to push $P_{2}$ downwards to satisfy zero-profit condition for sector 3 . However, under the sufficient condition $\lambda_{K 2} \cong 0$ (proportion of capital employed in sector 2 is negligible), $P_{2}$ rises. This will induce a Stolper-Samuelson effect in the Heckscher-Ohlin-Subsytem (HOSS) formed by sectors 1 and 2, owing to which competitive rural wage rises as sector 1 is relatively land-intensive than sector 2 in physical and value terms $\left(|\theta|<0,\left(\lambda_{L 1} \lambda_{N 2}-\lambda_{L 2} \lambda_{N 1}\right)<0\right)$.

Note that this again points to the possibility of jobless growth in the urban manufacturing sector:

(i) Joblessness: So from the above discussion it is clear that if $\lambda_{K 2} \cong 0$ and sector 1 is 
relatively land-intensive than sector 2: (1) Sector 3 will expand, (2) competitive wage $(W)$ and return to capital $(r)$ will rise, while (3) unionised wage $\left(W^{*}\right)$ will fall. As $\left(W^{*} / r\right)$ falls, producers in sector 3 will switch to more labour-intensive techniques of production than before. In other words, $a_{L 3}$ rises. So number of jobs available in the urban sector, $a_{L 3} X_{3}$, rises. As a result, every prospective rural migrant will be lured to migrate to the urban sector (sector 3 ) which accentuates the urban unemployment problem (centrifugal force). However since the unionised urban wage falls and competitive rural wage rises, the rural-urban wage gap falls. This prevents the rural workers from joining the urban unemployment pool (centripetal force).

From HT migration equilibrium we have

$$
L_{U}=\left[\left\{\left(\frac{W^{*}}{W}\right)-1\right\} a_{L 3} X_{3}\right]
$$

Totally differentiating both sides

$$
\widehat{L_{U}}=\underbrace{\frac{W^{*}}{\left(W^{*}-W\right)}\left(\widehat{W}^{*}-\widehat{W}\right)}_{<0 \text { (centripetal force })}+(\underbrace{\widehat{a_{L 3}}+\widehat{X_{3}}}_{>0(\text { centrifugal force })})
$$

It is again possible that these two opposite forces more or less equal, resulting stagnation in urban employment. Also sufficiently stronger centrifugal force could lead to enormous number of job losses.

(ii) Growth Effect: But note that as a result total wage-earnings rises, total rental income from land falls while return to capital remains unchanged. But as sector 3 expands, the cost of tariff protection on the supply side increases which works negatively on welfare. Of course social welfare may increase if the positive impact of rise in aggregate wage-earnings outweighs the negative forces. But that benefit will not accrue to the job-losers if there is no net job creation/significant loss in productive jobs in the economy. So the economy will again experience a jobless growth. 


\section{Policy Implications}

We make a theoretical prediction about the puzzling incidence of jobless growth which has made India's liberalisation policy a real contentious issue. We have theoretically discussed the consequences of trade liberalisation captured by a tariff-reform in the protected import-competing sector and liberalisation of labour laws captured by a reduction in the bargaining strength of the labour unions. This analysis has also been able to show

(i) Impact of trade liberalisation policy in the presence of labour market imperfection on the competitive rural (informal) wage when there is agricultural dualism in the rural economy; and

(ii) Labour market reforms, contrary to the conventional wisdom, may raise the competitive wage.

These results suggest that government needs to be very careful in the implementation of these different liberalisation policies to achieve welfare gains, while the latter result is extremely crucial in the context of an agro-dominated developing economy. The different theoretical models used here tries to show that economic reforms may lead to output growth without a growth in productive employment in the organised sector.

However, none of these policies can rule out the prediction of jobless growth. The growth-effect does not always trickle down to the job losers, leading to jobless growth in the organised sectors. That is precisely why increasing productive employment becomes a real challenge for a developing economy like India during this liberalised regime (World Bank 2013).

Received 8 June 2013, Revised 28 August 2013, Accepted 30 January 2014 


\section{References}

Bhaduri, A. (2007), "Development or developmental terrorism”, Economic and Political Weekly 42.

Bhalotra, S. (2002), "The Impact of Economic Liberalisation on Employment and wages in India", ILO, Geneva

Bhalotra, S. (1998), “The Puzzle of Jobless Growth in Indian Manufacturing”, Oxford Bulletin of Economics and Statistics, $60: 5-32$.

Chaudhuri, S. (2007), "Foreign capital, welfare and urban unemployment in the presence of agricultural dualism", Japan and the World Economy 19, 149-165.

Chaudhuri, S. and Mukhopadhyay, U. (2010), "Revisiting the Informal Sector: A General Equilibrium Approach", Springer, New York, 33-35.

Corden, W.M. and Findlay, R. (1975), "Urban unemployment, intersectoral capital mobility, and development policy in a dual economy", Economica 42 , 59-78.

Harris, J.R. and Todaro, M. (1970), "Migration, unemployment, and development: a two-sector analysis", American Economic Review 60 , 126-142.

Indiresan, P.V. (2002), "Vision 2020-the jobless growth conundrum", The Hindu Business Line, Internet Edition.

Jha, P. (2003), "Issues Relating to Employment in India in the Era of Globalisation", Social Scientist 31, 47-65.

Kaplinsky, R. (2001), "Globalization and Economic Insecurity”, IDS Bulletin 32, 1324.

Marjit, S. and Beladi, H. (1996), "Protection and the gainful effects of foreign capital", Economics Letters 53, 311-326.

Mukherjee, S. (2012), "Revisiting the Apparent Paradox: Foreign Capital Inflow, Welfare Amelioration and 'Jobless Growth' with Agricultural Dualism and Nontraded Intermediate Input", Journal of Economic Integration 27 , 123-133.

Nagraj, R. (2009), "Fall in Organised Manufacturing Employment: A Brief Note", Economic and political weekly, 39, 3387-3390. 
Sen, S. (2005), "India following America in jobless growth", India Daily 26 March, Internet Edition.

World Bank. (2013), “World Development Report 2013: Jobs", Washington, DC: The World Bank.

Yabuuchi, S., Beladi, H. (2001), “Urban unemployment, informal sector and development policies", Journal of Economics, 74, 301-314. 


\section{Appendices}

\section{Appendix A: Derivation of Some Algebraic Expressions}

$$
\begin{aligned}
& C_{1}=\frac{1}{|\theta|}\left[\begin{array}{c}
\left(\theta_{K 3}+\theta_{23} \theta_{K 2}\right) \bar{\lambda}_{L i} \bar{S}_{L j}^{k}+\theta_{N 1}\left(\theta_{K 3}+\theta_{23} \theta_{K 2}\right)\left(1-\lambda_{L 3}\right)- \\
\theta_{23}\left(\theta_{L 1} \theta_{N 2}-\theta_{N 1} \theta_{L 2}\right)\left(\lambda_{L 2} S_{L K}^{2}+\tilde{\lambda}_{L 3} S_{L K}^{3}\right)
\end{array}\right]<0 \\
& |\lambda|=\left(\lambda_{L 1} \lambda_{N 2} \lambda_{K 3}-\lambda_{L 2} \lambda_{N 1} \lambda_{K 3}+\tilde{\lambda}_{L 3} \lambda_{N 1} \lambda_{K 2}\right) \\
& \tilde{\lambda}_{L 3}=\left(\frac{W^{*}}{W}\right) \lambda_{L 3} \\
& \bar{\lambda}_{L i} \bar{S}_{L j}^{k}=\left(\lambda_{L 1} S_{L N}^{1}+\lambda_{L 2} S_{L N}^{2}+\lambda_{L 2} S_{L K}^{2} \theta_{N 1}\right)>0 \\
& \Delta=\left[C_{3}\left(\lambda_{L 1} \lambda_{N 2}-\lambda_{L 2} \lambda_{N 1}-\lambda_{N 1} \widetilde{\lambda_{L 3}}\right)-\lambda_{L 1} C_{2}-\lambda_{N 1} C_{1}\right] \\
& C_{2}=\left(\frac{1}{|\theta|}\right)\left[\left(\theta_{K 3}+\theta_{23} \theta_{K 2}\right) \bar{\lambda}_{N i} \bar{S}_{N j}^{k}-\theta_{23}\left(\theta_{L 1} \theta_{N 2}-\theta_{N 1} \theta_{L 2}\right) \lambda_{N 2} S_{N K}^{2}\right]<0 \\
& \bar{\lambda}_{N i} \bar{S}_{N j}^{k}=\left(\lambda_{N 1} S_{N L}^{1}+\lambda_{N 2} S_{N L}^{2}+\lambda_{N 2} S_{N K}^{2} \theta_{L 1}\right)>0 \\
& C_{3}=\left(\frac{1}{|\theta|}\right)\left[\left(\theta_{K 3}+\theta_{23} \theta_{K 2}\right)\left(1-S_{K K}^{2} \theta_{L 1}\right) \lambda_{K 2}-\theta_{23}\left(\theta_{L 1} \theta_{N 2}-\theta_{N 1} \theta_{L 2}\right) \lambda_{K 2}\left(S_{K L}^{2}+S_{K N}^{2}\right)\right]<0 \\
& C_{4}=\frac{T}{|\theta|}\left[\bar{\lambda}_{N i} \bar{S}_{N j}^{k} \theta_{K 2}-\left(\theta_{L 1} \theta_{N 2}-\theta_{N 1} \theta_{N 2}\right) \lambda_{N 2} S_{N K}^{2}\right]<0 \\
& C_{5}=\frac{T}{|\theta|}\left[\theta_{K 2} \bar{\lambda}_{L i} \bar{S}_{L j}^{k}-\left(\theta_{L 1} \theta_{N 2}-\theta_{N 1} \theta_{L 2}\right)\left(\lambda_{L 2} S_{L K}^{2}+\tilde{\lambda}_{L 3} S_{L K}^{3}\right)\right]<0 \\
& C_{6}=\frac{T}{|\theta|}\left[\theta_{K 2} \tilde{\lambda}_{L 3}\left(\theta_{L 1} S_{K K}^{2}-1\right)-\left(\theta_{L 1} \theta_{N 2}-\theta_{N 1} \theta_{N 2}\right) \lambda_{K 2}\left(S_{K L}^{2}+S_{K N}^{2}\right)\right]
\end{aligned}
$$

Where $S_{j k}^{i}$ is the degree of substitution between factors $j$ and $k$ in the $i^{\text {th }}$ sector $(j, k=L$, $N, K$ and $i=1,2,3)$. For example, $S_{K L}^{2}=\left(\partial a_{K 2} / \partial W\right)\left(W / a_{K 2}\right) . S_{j k}^{i}>0$ for $j \neq k$ and $S_{j j}^{i}<0$. 
Also,

$$
\begin{gathered}
B_{1}=\left(\frac{1}{|\theta|}\right)\left[\theta_{K 2} \theta_{L 3}\left(\lambda_{L 1} S_{L N}^{1}+\lambda_{L 2} S_{L N}^{2}+\lambda_{L 2} S_{L K}^{2} \theta_{N 1}\right)\right. \\
\left.-\left(\theta_{L 1} \theta_{N 2}-\theta_{N 1} \theta_{L 2}\right)\left\{\theta_{L 3} \lambda_{L 2} S_{L K}^{2}+\lambda_{L 3} S_{L K}^{3}\left(\theta_{L 3}+\theta_{K 3}\right)\right\}\right] \\
B_{2}=\frac{\theta_{L 3}}{|\theta|}\left[\theta_{K 2}\left(\lambda_{N 1} S_{N L}^{1}+\lambda_{N 2} S_{N L}^{2}+\lambda_{N 2} S_{N K}^{2} \theta_{L 1}\right)-\left(\theta_{L 1} \theta_{N 2}-\theta_{N 1} \theta_{L 2}\right) \lambda_{N 2} S_{N K}^{2}\right] \\
B_{3}=\frac{1}{|\theta|}\left[\theta_{K 2} \theta_{L 3} \lambda_{K 2}\left(\theta_{L 1} S_{K K}^{2}-1\right)\right. \\
\left.\quad-\left(\theta_{L 1} \theta_{N 2}-\theta_{N 1} \theta_{L 2}\right)\left\{\lambda_{K 2} \theta_{L 3}\left(S_{K L}^{2}+S_{K N}^{2}\right)+\lambda_{K 3} S_{K L}^{3}\left(\theta_{L 3}+\theta_{K 3}\right)\right\}\right]
\end{gathered}
$$

\section{Appendix B: Stability Condition in Non-traded Intermediate Input Market}

$P_{2}$, the price of non-traded intermediate input must adjust to clear its domestic market. Therefore, the stability condition for equilibrium in this market needs

$$
\left\{d\left(X_{2}^{D}-X_{2}\right) / d P_{2}\right\}<0
$$

That means around equilibrium, $X_{2}^{D}=X_{2}$. Therefore,

$$
\left\{\left(\widehat{X}_{2}^{D} / \widehat{P_{2}}\right)-\left(\widehat{X_{2}} / \widehat{P_{2}}\right)\right\}<0
$$

Now $X_{2}^{D}=a_{23} X_{3}$ is the demand for non-traded input. Totally differentiation gives, $\widehat{X}_{2}^{D}$ $=\widehat{X}_{3}$. Using Equations (13) and (14), we get

$$
\begin{aligned}
& \left(\frac{\widehat{X}_{2}}{\widehat{P}_{2}}\right)=\left(\frac{1}{|\lambda|}\right)\left(\lambda_{N 1} \lambda_{K 3} C_{1}+\lambda_{L 1} \lambda_{K 3} C_{2}+\lambda_{N 1} \widetilde{\lambda}_{L 3} C_{3}\right) \\
& \Delta=\left[C_{3}\left(\lambda_{L 1} \lambda_{N 2}-\lambda_{L 2} \lambda_{N 1}-\lambda_{N 1} \widetilde{\lambda}_{L 3}\right)-\lambda_{L 1} C_{2}-\lambda_{N 1} C_{2}\right]
\end{aligned}
$$


Using Equations (B1) (B3) we get the required stability condition

$$
\frac{\Delta}{|\lambda|}<0
$$

where

$$
\Delta=\left[C_{3}\left(\lambda_{L 1} \lambda_{N 2}-\lambda_{L 2} \lambda_{N 1}-\lambda_{N 1} \widetilde{\lambda_{L 3}}\right)-\lambda_{L 1} C_{2}-\lambda_{N 1} C_{2}\right] \quad \text { (Q.E.D.) }
$$

